\title{
Differential CXCR4 expression and function in subpopulations of the feline lymphoma cell line 3201 susceptible to feline immunodeficiency virus.
}

\section{AUTHOR(S):}

Tochikura, Tadafumi S; Motokawa, Kenji; Naito, Yuko; Kozutsumi, Yasunori; Tanabe-Tochikura, Akiko; Hohdatsu, Tsutomu

\section{CITATION:}

Tochikura, Tadafumi S ... [et al]. Differential CXCR4 expression and function in subpopulations of the feline lymphoma cell line 3201 susceptible to feline immunodeficiency virus.. Journal of feline medicine and surgery 2010, 12(4): 269-277

\section{ISSUE DATE:}

2010-04

\section{URL:}

http://hdl.handle.net/2433/128856

\section{RIGHT:}

(c) 2009 ISFM and AAFP Published by Elsevier Ltd.; This is not the

published version. Please cite only the published version.; この論文は 出版社版でありません。引用の際には出版社版をご確認ご利用くださ い。 
Differential CXCR4 Expression and Function in Subpopulations of the Feline Lymphoma

Cell Line 3201 Susceptibile to Feline Immunodeficiency Virus

Tadafumi S Tochikura DVM, PhD ${ }^{1 *}$, Kenji Motokawa DVM, $\mathrm{PhD}^{2}, \quad$ Yuko Naito $\mathrm{PhD}^{3}$,

Yasunori Kozutsumi PhD ${ }^{3}, \quad$ Akiko Tanabe-Tochikura PhD ${ }^{4}$, Tsutomu Hohdatsu DVM, PhD ${ }^{5}$

${ }^{1}$ Center for Integrative Education of Pharmacy Frontier, Graduate School of Pharmaceutical Sciences, Kyoto University, Sakyo-ku, Kyoto 606-8501, Japan

${ }^{2}$ The Kitasato Institute Research Center for Biologicals, Kitamoto, Saitama 364-0026, Japan

${ }^{3}$ Laboratory of Membrane Biochemistry and Biophysics, Graduate School of Biostudies, Kyoto University, Sakyo-ku, Kyoto 606-8501, Japan

${ }^{4}$ Department of Pathology, Research Institute for Microbial Diseases, Osaka University, Suita, Osaka 565-0871, Japan

Present address: Sugi Pharmacy, Co.,Ltd, Ukyo-ku, Kyoto 615-0011, Japan

${ }^{5}$ Department of Veterinary Infectious Diseases, School of Veterinary Medicine and Animal Sciences, Kitasato University, Towada, Aomori 034-8628, Japan 
${ }^{\star}$ Correspondence to :

Dr. Tadafumi S.Tochikura

Center for Integrative Education of Pharmacy Frontier

Graduate School of Pharmaceutical Sciences

Kyoto University, Sakyo-ku, Kyoto 606-8501, Japan

TEL : +81-75-753-4564

FAX : +81-75-761-2698

E-mail address : tad@pharm.kyoto-u.ac.jp 


\section{Abstract}

The infection of feline thymic lymphoma 3201 cells with a cell culture-adapted Petaluma strain of feline immunodeficiency virus (FIV) led to the establishment of survivor cells designated as 3201-S after a productive infection associated with extensive cell killing. $3201-\mathrm{S}$ cells were free of FIV DNA, and were found to express CXCR4, a coreceptor for infection but not CD134, a primary receptor. When $3201-\mathrm{S}$ cells were reinfected with FIV, viral DNA was transiently detectable for 5 days postinfection, indicating that 3201-S cells cannot support the FIV replicative cycle. Furthermore, comparative studies found that in contrast to SDF-1a-responsive 3201 cells, 3201-S cells did not show a flux of $\mathrm{Ca}^{2+}$ in response to SDF-1 $\alpha$, implying that CXCR4 is not functionally active on 3201-S cells. These results suggest that 3201 cells can be heterogeneous in the phenotype of the CXCR4 expressed, and this heterogeneity may account for the differences in susceptibility to FIV. Determining the mechanism(s) within 3201-S cells that restrict FIV could result in therapeutic strategies against FIV infection. 


\section{Introduction}

The development of appropriate animal models of acquired immunodeficiency syndrome (AIDS) is critical to better understand the pathogenesis of lentivirus-induced immune deficiency which is etiologically linked to human immunodeficiency virus type 1 (HIV-1). ${ }^{1}$ Only two animal lentiviruses have thus far been implicated in AIDS-like diseases, feline immunodeficiency virus $(\mathrm{FIV})^{2}$ and simian immunodeficiency virus (SIV). ${ }^{3}$ The use of SIV in macaques provides an opportunity to evaluate a primate lentivirus within a species closely related to humans. A major concern, however, is the relative shortage of non-human primates available for infectivity trials as well as for safety and efficacy studies on candidate vaccines and antiviral drugs. The advantages of a feline model of AIDS are not only the similarities to human AIDS, but also practicality and cost compared with the use of non-human primates. ${ }^{4}$ As with HIV, FIV primarily targets $\mathrm{CD}^{+} \mathrm{T}$ cells, but it uses CD134, a $\mathrm{T}$ cell activation and co-stimulatory molecule, and not CD4 as a primary receptor, ${ }^{5,6}$ inducing an AIDS-like immunodeficiency in its natural host species due to a progressive depletion of $\mathrm{CD}^{+}{ }^{\mathrm{T}}$ cells. ${ }^{7}$ The feline animal model thus provides the research community with a well-established research species and an easily handleable animal. Moreover, FIV has the advantage that a high level of biocontainment at laboratory facilities is not required, thereby representing a valuable model for HIV/AIDS research. This model has already been used for the testing of antiviral drugs. ${ }^{8-10}$

We have described earlier that the feline lymphoma cell line 3201 was highly susceptible to the cytopathic effects of FIV-Petaluma. Moreover, 3201 cells that survived FIV infection established a chronic FIV-producer cell line (3201/FIV) during a chase period of 2 months. ${ }^{11}$ 
Recently, we repeated this experiment and found that the 3201/FIV cell line was established consistent with our earlier observations, but the frequency of FIV antigen-positive cells decreased gradually over time during further incubation. On day 86 postinfection, none of the FIV-surviving cells which were designated as 3201-S was any longer positive for viral antigens. This is of interest considering that $3201-\mathrm{S}$ cells have not yet been characterized.

In the present study, we demonstrated that viral DNA was no longer detected in 3201-S cells. Although proviral DNA was detected in the FIV-reinfected 3201-S cells early in the infection, the viral genome was no longer detectable afterwards, suggesting that 3201 -S cells were unable to support detectable viral replication. Since it has been reported that 3201 cells express relatively high levels of CXCR4, a chemokine receptor whose natural ligand has been identified as the chemokine SDF-1 (stromal cell derived factor), necessary for the efficient infection of target cells, ${ }^{12,13}$ we first assessed the 3201-S cells for CXCR4 expression by flow cytometric analysis using a panel of CXCR4 monoclonal antibodies recognizing antigenically distinct conformations of CXCR4. ${ }^{14} \quad$ We have found that both 3201 and $3201-S$ cells express this chemokine receptor, although the parental 3201 cells could be distinguished from $3201-\mathrm{S}$ cells in that the former cells express higher levels of CXCR4 with respect to fluorescence intensity. Of particular interest to the present study, 3201-S cells were unable to support the viral replicative cycle after reinfection with FIV. Furthermore, SDF-1a stimulates calcium mobilization in 3201 but not in 3201-S cells, suggesting that the receptor is not functional in 3201-S cells. These findings led us to hypothesize that phenotypic heterogeneity exists in the original 3201 cells and their differential expression of CXCR4 may influence CXCR4-dependent FIV entry and 
responsiveness to SDF-1 $\alpha$. Our data could have important implications for understanding intrinsic resistance to the virus in infected animals. 


\section{Materials and methods}

\subsection{Cells}

3201 cells,${ }^{15}$ kindly provided by Dr.Lawrence Mathes (The Ohio State University, Columbus,

$\mathrm{OH}$, USA), are a feline thymic lymphoma cell line. Cells were cultured in a medium consisting of equal parts Leibovitz L-15 medium and RPMI 1640 medium supplemented with $10 \%$ heat-inactivated fetal bovine serum (FBS), penicillin (100 IU/ml) and streptomycin $(100 \mu \mathrm{g} / \mathrm{ml})$. 3201 cells were routinely passaged $1: 5$ every 3 to 4 days and incubated at $37^{\circ} \mathrm{C}$. Feline peripheral blood mononuclear cells (PBMCs) were obtained from a specific-pathogen-free (SPF) adult cat (Shimizu Laboratory Supplies, Kyoto, Japan). The PBMCs were initially stimulated with $5 \mu \mathrm{g}$ of phytohemaglutinin (PHA) per $\mathrm{ml}$ for 3 days, maintained on $5 \mathrm{ng}$ of recombinant human interleukin-2 (IL-2) per ml, and replenished with fresh PHA and IL-2-stimulated PBMCs in a complete RPMI 1640 medium with $20 \%$ FBS every 5 to 7 days.

\subsection{Antibodies}

The following antibodies were used in this study : mouse anti-feline/human CXCR4 monoclonal antibodies (MAbs) - clones 44708 and 44716 (NIH AIDS Research and Reference Reagent Program, Rockville, MD, USA), and clone 44717 (R\&D Systems, Minneapolis, MN, USA) ; anti-CD134 MAb reacting with feline CD134 but only weakly with human CD134 (Affinity BioReagents, Golden, CO, USA) ; sera from FIV-infected cats (kindly provided by Dr.Makoto Hitomi and Dr.Haruo Konishi) and control plasma from an uninfected SPF cat (Shimizu Laboratory Supplies,Kyoto,Japan). 


\subsection{Preparation of virus}

A cell culture-adapted strain of FIV-Petaluma was obtained from the NIH AIDS Research and Reference Reagent Program (Rockville, MD, USA). Tissue culture supernatant from 3201 cells persistently infected with FIV(3201/FIV) was used as a source of infectious virus. After more than $80 \%$ of the 3201 cells became positive for FIV antigens, as detected with an indirect immunofluorescence assay (IFA), the culture supernatant was filtered through a $0.45 \mu \mathrm{m}$ Millipore membrane filter and stored at $-70^{\circ} \mathrm{C}$ in small aliquots until used. The viral titer was $10^{3.8} 50 \%$ tissue culture infectious dose per ml assayed in 3201 cells. $^{11}$

\subsection{Infection}

Target cells were infected with FIV at a multiplicity of infection (M.O.I.) of 0.04. After the adsorption of FIV at $37^{\circ} \mathrm{C}$ for $1 \mathrm{~h}$, cells were cultured in complete medium at $37^{\circ} \mathrm{C}$ in $5 \% \mathrm{CO}_{2}$. The cells were subcultured every 3 to 4 days. The efficiency of viral infection was analyzed based on cell viability, monitored with the trypan blue dye exclusion test, and by IFA. ${ }^{11}$

\subsection{Immunofluorescence assay (IFA)}

The expression of FIV antigen in FIV-infected cells was detected by indirect immunofluorescence microscopy. ${ }^{11} \quad$ Cells were smeared on microscope slides and air-dried. Smeared cells were fixed with cold methanol for $15 \mathrm{~min}$ and air-dried. The slides were incubated for $45 \mathrm{~min}$ at $37^{\circ} \mathrm{C}$ in a humidified atmosphere with a 1:400 dilution of serum from an 
FIV-infected cat (IFA titer to FIV ; 1:2,560) or control plasma from an uninfected SPF cat. The slides were then washed twice in PBS and incubated for 30 min at $37^{\circ} \mathrm{C}$ with fluorescein-isothiocyanate (FITC)-conjugated anti-cat IgG (Serotec, Raleigh, NC, USA). The slides were next washed twice with PBS, and mounted with $50 \%$ glycerol in PBS. Positive cells were examined by epifluorescence microscopy. For the calculation of percentage, over 500 cells were counted.

\subsection{Flow cytometry}

Flow cytometric analyses were performed as described previously ${ }^{16}$ with minor modifications. Briefly, $2 \times 10^{5}$ cells were washed by centrifugation and resuspended in FACS buffer ([1\% FBS PBS $]+0.1 \%$ sodium azide). Cells were then incubated with anti-CXCR4 MAbs or anti-CD134 MAb for 40 min at room temperature. After being washed with PBS, cells were incubated with FITC-conjugated anti-mouse IgG (Cappel) in the dark for $20 \mathrm{~min}$ at room temperature. After another wash with PBS, stained cells were resuspended in FACS buffer, examined with a FACScan flow cytometer (Becton Dickinson, San Jose, CA, USA), and then analyzed using FlowJo software (Tree Star, Ashland, OR, USA). Data were collected from approximately 10,000 events for each experimental condition, and results are expressed as mean fluorescence intensity (MFI) and a single-parameter log fluorescence histogram.

\subsection{Polymerase chain reaction (PCR)}

Petaluma $^{17}$ FIV gag and envelope (env) genes were amplified by nested PCR as described 
previously. ${ }^{18,19}$ Briefly, a 329-base pair (bp) fragment corresponding to the region from 1036 to 1364 of the gag gene was generated with an outer primer set (sense, nucleotides 917-936, 5'-AATATGACTGTATCTACTGC-3';antisense, nucleotides 1650-1628, 5'-TTTTCTTCTAGAGTACTTTCTGG-3') and an inner primer set (sense, nucleotides 1036-1055, 5'-TATTCAAACAGTAAATGGAG-3';antisense, nucleotides $1364-1345$ 5'-CTGCTTGTTGTTCTTGAGTT-3'). An 873-bp fragment, corresponding to the region from 7207 to 8079 of the env gene, was generated with an outer primer set (sense, nucleotides 7032-7053， 5'-GATGGAATGAGACTATAACAGG-3';antisense， nucleotides 8119-8098, 5'-CAACATAACATGAATAGCTGCC-3') and an inner primer set (sense, nucleotides 7207-7230, 5'-CCAACAATTAAGTTATTGTACAGA-3'; antisense, nucleotides 8079-8058, 5'-TATTCCATGACTTCCTCTGGGA-3'). PCR was performed in 0.2-ml microfuge tubes in a total volume of $50 \mu \mathrm{l}$. A DNA sample (a DNA amount equivalent to $2 \times 10^{5}$ cells in $10 \mu \mathrm{l}$ ) was added to $5 \mu \mathrm{l}$ of 10 -fold concentrated reaction buffer (Takara, Kyoto, Japan), $5 \mu \mathrm{l}$ of deoxynucleotide mix (Takara, Kyoto, Japan) containing $2.5 \mathrm{mM}$ of each, $2 \mu \mathrm{l}$ of $20 \mu \mathrm{M}$ primer mix,

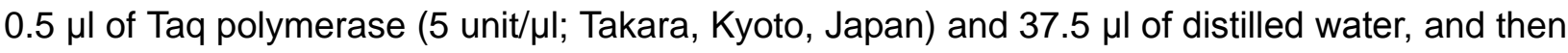
mixed. The DNA was amplified with a DNA thermal cycler (Applied Biosystems, Foster, CA, USA). The amplification involved incubation for $5 \mathrm{~min}$ at $94^{\circ} \mathrm{C}$ as the first denaturation, followed by 30 cycles of denaturation for $1 \mathrm{~min}$ at $94^{\circ} \mathrm{C}$, primer annealing for $1 \mathrm{~min}$ at $55^{\circ} \mathrm{C}$ and synthesis for $1.5 \mathrm{~min}$ at $72^{\circ} \mathrm{C}$, and a final incubation for $5 \mathrm{~min}$ at $72^{\circ} \mathrm{C}$. The nested PCR products were electrophoresed through a $2 \%$ agarose gel. The gel was incubated with ethidium bromide, and the bands were visualized by a UV transilluminator at $312 \mathrm{~nm}$, and then photographed. 
The real-time PCR assay was performed with an DNA Engine Opticon Real-Time PCR Detection System (Bio-Rad, Hercules, CA, USA) by using a QuantiTect SYBR Green PCR Kit (QIAGEN K.K., Tokyo, Japan) according to the manufacturer's instructions. Briefly, each sample was amplified in a final volume of $20 \mu$ l containing $10 \mu l$ of $2 x$ Quantitect SYBR Green PCR Master Mix, $0.3 \mu \mathrm{M}$ of inner primer for the gag gene whose sequence was the same as that used for the nested PCR, and $5 \mu$ of extracted DNA dilution (sample) or a recombinant DNA plasmid encoding for a FIV gag protein derived from the Aomori 2 strain. ${ }^{20}$ Cycling parameters were $15 \mathrm{~min}$ at $95^{\circ} \mathrm{C}$ for the hot start Taq polymerase activation followed by 55 cycles of $15 \mathrm{~s}$ at $94{ }^{\circ} \mathrm{C}, 30 \mathrm{~s}$ at $55^{\circ} \mathrm{C}$ and $30 \mathrm{~s}$ at $72{ }^{\circ} \mathrm{C}$. The reaction was carried out testing all the samples and five standard plasmid dilutions in duplicate together with a no-template control.

\subsection{Calcium flux measurements}

Calcium flux in response to SDF-1a was measured using a modification of a method described previously. ${ }^{16}$ Either 3201 or $3201-S$ cells were loaded with a fluorescent probe, Indo-1 AM (1 $\mu \mathrm{M}$; Dojindo, Tokyo, Japan), in RPMI 1640 medium for 30 min at $37^{\circ} \mathrm{C}$. The cells were washed twice with Hanks' Balanced Salt Solution (HBSS), and then adjusted to $5 \mathrm{x}$ $10^{5} \mathrm{cells} / \mathrm{ml}$ in HBSS. After pre-heating for $5 \mathrm{~min}$ at $37^{\circ} \mathrm{C}$, the cells were stimulated with SDF-1 $\alpha(1 \mu \mathrm{g} / \mathrm{ml}$, recombinant human SDF-1 $\alpha$; PeproTech, London, UK).

Fluorescent emissions at wavelengths of 405 and $485 \mathrm{~nm}$ were monitored upon excitation at $338 \mathrm{~nm}$ using a spectrofluorometer RF-1500 (Shimadzu, Kyoto, Japan). The calculation of the 
change in intracellular $\mathrm{Ca}^{2+}$ concentrations in combination with digitonin permeabilization and EGTA treatment was done using the Intracellular $\mathrm{Ca}^{2+}$ Measurement Program Pack according to the manufacturer's instructions (Shimadzu, Kyoto, Japan). 


\section{Results}

\subsection{Establishment of 3201 cells surviving FIV infection}

After the exposure of 3201 cells to cell-free culture fluids derived from the 3201/FIV cell culture, continuous growth of the infected cells and production of FIV were observed as described previously, ${ }^{11}$ however, the frequency of FIV antigen-positive cells decreased gradually over time during further incubation. When the surviving cells were evaluated at 86 days postinfection (dpi) for their ability to be a reservoir of FIV, neither infectious virus nor FIV antigen-expressing cells could be detected by IFA even after treatment with IUdR or phorbol myristate acetate, a well-known inducer of retroviruses (data not shown). ${ }^{21,}{ }^{22}$ The nonvirus-producing survivor cells, here referred to as 3201-S, were indistinguishable in morphology and growth rate from mock-infected 3201 cells (data not shown).

To determine if FIV cDNA was present in the FIV-surviving 3201-S cells after exposure to FIV, samples were examined by nested PCR. DNA isolated from cell cultures derived from virus-producing 3201/FIV cells showed the 329-bp and 873-bp products specific to FIV gag and env, respectively, whereas no specific bands were detected in samples from 3201-S and mock-infected 3201 cells (Fig.1).

\subsection{Absence of CD134 expression in 3201 cells}

CD134 has been reported to be expressed in PBMCs and interleukin-2-dependent $\mathrm{T}$ cell lines, and to represent a primary target of FIV. ${ }^{5}$ An analysis was undertaken next to determine whether CD134 expression might be involved in FIV infections among 3201 cell derivatives. 
Consistent with previous findings that 3201 cells lack CD134 expression, ${ }^{6}$ the binding of anti-CD134 MAb, detected by flow cytometry and indicated as mean fluorescence intensity (MFI), was observed on activated PBMCs used as a positive control but not on 3201 or $3201-\mathrm{S}$ cells (more than a 5-fold difference in MFI, data not shown), confirming that CD134 is not likely to contribute to FIV infection in 3201 cells.

\subsection{Presence of CXCR4 expression in 3201 and $3201-S$ cells}

It has been shown that 3201 cells express relatively high levels of CXCR4, used by FIV for infection. ${ }^{12,13}$ The cell-surface expression of CXCR4 on 3201, 3201-S, and 3201/FIV cells was next evaluated by flow cytometry using anti-CXCR4 44717 MAb. As shown in Fig.2, a profound shift was seen in the fluorescence histogram of anti-CXCR4 stained cells when compared to the background (FITC-conjugated secondary antibody alone), indicating the presence of cell surface CXCR4 protein on 3201 cells. The amount of CXCR4 was markedly reduced in the FIV-infected 3201 cells, with more than $90 \%$ of the cells positive for FIV antigens. This finding is in agreement with a report that the surface expression of CXCR4 was markedly reduced on Crandell feline kidney (CRFK) cells after FIV infection, presumably due to either a down-regulation of CXCR4 expression or the elimination of CXCR4-expressing cells from the culture. ${ }^{12}$ Of particular interest is that approximately $45 \%$ of the cells in the $3201-\mathrm{S}$ culture were recognized by the MAb, albeit with a low intensity, compared to almost $100 \%$ and $2 \%$ (1.6-fold above the background level) of the cells in 3201 and 3201/FIV controls, respectively (data not shown). This will be discussed later. 
Given previous reports that CXCR4 existed in antigenically distinct states in most cell types, presumably due to conformational heterogeneity, ${ }^{14}$ we investigated the ability of other two commercially available MAbs against CXCR4 (clones 44708 and 44716), compared with that of clone 44717, to recognize CXCR4 on 3201-S cells as well as on 3201 cells. In agreement with previous findings that clone 44717 reacted with feline CXCR 4 most efficiently among the three MAbs, ${ }^{14} 3201$ cells appeared to express CXCR4 at the highest levels when stained with clone 44717 (Fig.3). We therefore selected clone 44717 for further studies.

\subsection{Demonstration of the presence of FIV DNA in FIV-reinfected 3201-S cells}

To study the susceptibility of 3201-S cells to FIV reinfection, the cells were exposed to the culture supernatant of $3201 /$ FIV cells at a M.O.I. of 0.04 . Viral antigens of FIV were first detected in 3201 cells by IFA as early as $3 \mathrm{dpi}$, and the frequency of detection increased gradually with time reaching more than $90 \%$ within a week (data not shown), whereas 3201-S cells remained negative indistinguishably from mock-infected 3201 cells during a 3-month culture period (data not shown). To further confirm the failure of FIV to reinfect $3201-S$ cells, DNA was extracted 5, 15 and 30 dpi from 3201-S cells that had been reinfected with FIV and analyzed for FIV sequences by PCR amplification. Interestingly, FIV DNA was detected in the 3201-S cells reinfected with FIV 5 dpi by nested PCR, the copy number determined by real-time PCR being 4 to 7 per $10^{6}$ cells, whereas FIV-infected 3201 cells tested positive for FIV throughout the experiment (Table 1). However, the viral genome in the FIV-reinfected 3201-S cells was no longer detectable at the subsequent testing points, indicating that FIV infection of 3201-S cells 
is inefficient compared to that of parental 3201 cells.

\subsection{Effect of FIV reinfection on the expression of CXCR4 on 3201-S cells.}

Since FIV DNA was detected in the 3201-S cells at 5 dpi (Table 1), we investigated the effect of FIV reinfection on CXCR4 expression on 3201-S cells (Fig.4). While approximately $20 \%$ of $3201-S$ cells expressed CXCR4 before FIV reinfention compared to $99 \%$ of 3201 cells, a similar proportion of $\mathrm{CXCR}^{+}$cells, ranging from $10 \%$ to $30 \%$, was maintained over the course of the culture up to 30 dpi on the FIV-reinfected 3201-S cells (data not shown). Newly infected 3201 cells exhibited a profound decrease in CXCR4 cell surface expression, consistent with Figs. 2 and 3, in which the frequency of FIV antigen -positive cells in the culture was $81 \%, 95 \%$, and $90 \%$ at 5, 15, and $30 \mathrm{dpi}$, respectively (data not shown). These results indicated that the level of CXCR4 expression on 3201-S cells was not likely to be affected by FIV infection.

\subsection{CXCR4 is not functional on $3201-5$ cells.}

The activation of calcium flux in CXCR4-expressing human cells is related to HIV infection and as reported, stimulation of CXCR4 by SDF-1a increases calcium flux in several HIVsusceptible cell types. ${ }^{16,23}$ Thus, we became interested in whether $3201-S$ cells will respond to SDF-1 $\alpha$ through calcium flux, and conducted a calcium mobilization experiment to determine whether the CXCR4 expressed by 3201-S cells is a functional receptor. As shown in Fig.5, SDF-1 $\alpha$, whose concentration used in this study has previously been shown to stimulate CXCR4 to near maximal levels, ${ }^{23}$ clearly increased the intracellular $\mathrm{Ca}^{2+}$ level in the original 3201 cells. 
In contrast, SDF-1a failed to stimulate a response in 3201-S cells, suggesting that CXCR4 is not functionally active on 3201-S cells. 


\section{Discussion}

The primary receptor for FIV is CD134, a member of the tumor necrosis factor receptor superfamily, which is specifically expressed on activated CD4 ${ }^{+}$T cells. ${ }^{5,6}$ FIV infection requires the expression of a co-receptor, the chemokine receptor CXCR4, ${ }^{24}$ and the virus binds these receptors via its surface glycoprotein gp95. Some primary and cell culture-adapted strains of FIV such as Petaluma, however, can infect in the absence of CD134. ${ }^{5}$ CD134-independent FIV infection is mediated by direct interaction with CXCR4, ${ }^{24}$ analogous to infection with CD4-independent strains of HIV. ${ }^{25}$ In research on FIV, the 3201 cell line is often used as an in vitro model. ${ }^{6,11,18}$ Our present observation is consistent with the previous finding that 3201 cells abundantly express CXCR4 but not CD134. ${ }^{6,12,13}$ It can thus be concluded from these studies that CD134 is not likely to be involved in the infection of 3201 cells by FIV.

We focused on CXCR4 expression in 3201-S cells, and examined whether its down-regulation may account for the inability of FIV to reinfect 3201-S cells. Interestingly, we demonstrated by flow cytometric analysis that 3201 cells vary in their affinity for feline CXCR4 staining with three MAbs (clones 44708, 44716, and 44717) in the following order : 44717 > $44708>44716$ (Fig.3). CXCR4 possesses four extracellular domains: an N-terminal region and three extracellular loops (ECL1, ECL2, and ECL3). ${ }^{14}$ Based on epitope mapping using a panel of MAbs including clones 44708, 44716, and 44717, it seems likely that conformational differences in the CXCR4 ECL domains, in particular in ECL2, are responsible for the CXCR4 antigenic heterogeneity. Our finding that clone 44717 exhibited the strongest affinity for feline CXCR4 among the three MAbs was consistent with that reported for a transformed human T cell 
line, ${ }^{14}$ confirming that CXCR4 on 3201 cells similarly exhibits considerable conformational heterogeneity. Feline CXCR4 displayed $94.9 \%$ amino acid sequence identity with human $\mathrm{CXCR} 4,{ }^{24}$ and since the MAbs used in the present study react specifically not only with human and non-human cells expressing human CXCR4, but also with cells expressing feline CXCR4, ${ }^{14}$ it is conceivable that this may also be related to the level of cross-reactivity between human and feline CXCR4 at the particular epitope recognized by the MAbs.

The presence of FIV DNA in the 3201-S cells at 5 dpi, albeit at an extremely low frequency, suggests that $3201-S$ cells are reinfectable by FIV as determined by the PCR assay, however, FIV failed to spread in 3201-S cells as demonstrated by the lack of any persistent presence of viral DNA (Table 1). Calcium flux experiments showed that 3201 cells but not $3201-\mathrm{S}$ cells responded to SDF-1 $\alpha$ with a rapid mobilization of calcium, suggesting that CXCR4 is functionally active and is able to couple to G-protein signaling mechanisms, ${ }^{26}$ as opposed to $3201-\mathrm{S}$ cells whose CXCR4 receptor is likely to be dysfunctional. Our interpretation of these results is that 3201 cells grow as heterogeneous populations that are present in the starting culture prior to FIV infection. One population, representing the majority of the culture, expresses CXCR4 which supports FIV infection, but the others, comprising an extremely small number of cells, do not confer susceptibility to FIV infection possibly due to insufficient levels of CXCR4 expression. After the productive infection of 3201 cells, FIV-infected cells accompanied by viral antigens were probably eliminated from the culture due to cytopathic effects, and a small percentage of the cells no longer susceptible to FIV infection survived to replace the former population. Although little is known about why 3201 -S cells are unable to serve as a reservoir for FIV, at least 
two models can be considered. In the first model, CXCR4 is impaired, though it remains to be seen whether this would be due not only to its relatively low constitutive levels, but also the extremely small percentage of cells involved in the expression, or CXCR4 differs either structurally or functionally between 3201 and 3201-S cells, with FIV infection and responsiveness to SDF-1 $\alpha$. The role of chemokines such as the $\beta$-chemokines RANTES, MIP-1 $\alpha$, and MIP-1 $\beta$ in natural resistance to infection by HIV-1 has been established, with highly exposed persistently seronegative individuals found to be homozygous for a 32-bp deletion in the CCR5 gene encoding a receptor for those $\beta$-chemokines, and another co-receptor for HIV-1. ${ }^{27}$ If this should be the case with the CXCR4 observed in 3201-S cells, the dysfunctional CXCR4 may contribute to protection from FIV. Alternatively, in the second model, 3201-S cells carry restriction factors that confer resistance to replication by FIV. Recent in vitro studies showed that the existence of resistance factors (e.g., Lv1, Ref1, and TRIM5a, etc) in various species of animals can inhibit a range of retroviruses including lentiviruses by targeting the capsid of incoming viruses to block infection, indicating susceptibility to retroviral infection to be determined, in part, by host genes with antiviral activity. ${ }^{28,29}$ Our results thus suggest that the post-entry pathway followed by FIV could differ in 3201-S cells compared to parental 3201 cells. It remains to be elucidated whether similar restriction factor(s) participate in the inhibition of FIV replication in 3201-S cells.

In conclusion, it would appear that 3201 cells can be heterogeneous in the phenotype of the CXCR4 expressed, and this heterogeneity may account for the differences in susceptibility to FIV. Thus, 3201-S cells represent the first unique subpopulation of CXCR4 ${ }^{+} \mathrm{T}$ cells that are resistant 
to FIV replication, and may emerge as a consequence of selection during infection. Taken together, these findings may provide the basis for further studies to understand the role of 3201-S cells during FIV infection and identify host factors that could restrict the virus. 


\section{Acknowledgements}

We are grateful to Dr.Nobuyuki Ito, Dr.Nobutaka Fujii and especially the late Dr.James

R.Blakeslee,Jr. for their constant support and encouragement, and Dr.Hiromu Takematsu and Masakazu Ohashi for their technical assistance. We also wish to thank Dr.Ulrike Ziegner and Dr.Karin Nielsen for critically reviewing the manuscript and helpful discussions. The following reagents were obtained through the NIH AIDS Research and Reference Reagent Program, Division of AIDS (DAIDS), NIAID, NIH as indicated (Reagent Program catalog numbers are shown in parentheses) : FIV-Petaluma (236) from Dr.Niels Pedersen and Dr. Janet Yamamoto ; CXCR4 Monoclonal 44708 (4084) from DAIDS, NIAID, produced by R\&D Systems ; CXCR4 Monoclonal 44716.111 (4085) from DAIDS, NIAID. 


\section{References}

1. Levy JA. Pathogenesis of human immunodeficiency virus infection. Microbiol Rev $1993 ; 57$ : $183-289$.

2. Pedersen NC, Ho E, Brown ML, Yamamoto JK. Isolation of a T-lymphotropic virus from domestic cats with an immunodeficiency-like syndrome. Science $1987 ; 235: 790$ - 93.

3. Letvin NL, Daniel MD, Sehgal PK, et al. Induction of AIDS-like disease in macaque monkeys with T-cell tropic retrovirus STLV-III. Science $1985 ; 230: 71$ - 3.

4. Pedersen NC, Yamamoto JK, Ishida T, Hansen H. Feline immunodeficiency virus infection. Vet Immunol Immunopathol $1989 ; 21: 111$ - 29.

5. Shimojima M, Miyazawa $T$, keda $\mathrm{Y}$, et al. Use of CD134 as a primary receptor by the feline immunodeficiency virus. Science $2004 ; 303: 1192$ - 5 .

6. de Parseval A, Chatterji U, Sun P, Elder JH. Feline immunodeficiency virus targets activated CD4 $^{+}$T cells by using CD134 as a binding receptor. Proc Natl Acad Sci USA $2004 ; 101$ : $13044-9$.

7. English RV, Johnson CM, Gebhard DH, Tompkins MB. In vivo lymphocyte tropism of feline 
immunodeficiency virus. J Virol $1993 ; 67: 5175$ - 86.

8. Egberink $\mathrm{H}$, Borst $\mathrm{M}$, Niphuis $\mathrm{H}$, et al. Suppression of feline immunodeficiency virus infection in vivo by 9-(2-phosphonomethoxyethyl)adenine. Proc Natl Acad Sci USA $1990 ; 87$ : 3087-91.

9. Lafrado LJ, Podell M, Krakowka S, Hayes KA, Hanlon MA, Mathes LE. FIV : A model for retrovirus-induced pathogenesis. AIDS Rev $1993 ; 3: 115$ - 48.

10. Oishi S, Kodera $\mathrm{Y}$, Nishikawa $\mathrm{H}$, et al. Design and synthesis of membrane fusion inhibitors against the feline immunodeficiency virus. Bioorg Med Chem $2009 ; 17: 4916-20$.

11. Tochikura TS, Hayes KA, Cheney CM, et al. In vitro replication and cytopathogenicity of the feline immunodeficiency virus for feline T4 thymic lymphoma 3201 cells. Virology $1990 ; 179$ : 492-7.

12. Hosie MJ, Broere N, Hesselgesser J., et al. Modulation of feline Immunodeficiency virus Infection by stromal cell-derived factor. J Virol $1998 ; 72: 2097-104$.

13. Endo $\mathrm{Y}$, Goto $\mathrm{Y}$, Nishimura $\mathrm{Y}$, et al. Inhibitory effect of stromal cell derived factor-1 on the replication of divergent strains of feline immunodeficiency virus in a feline T-lymphoid cell line. Vet Immunol Immunopathol $2000 ; 74: 303-14$. 
14. Baribaud F, Edwards TG, Sharron M, et al. Antigenically distinct conformations of CXCR4.

J Virol $2001 ; 75: 8957-67$

15. Snyder HW Jr, Hardy WD Jr, Zuckerman EE, Fleissner E. Characterisation of a ttumor-specific antigen on the surface of feline lymphosarcoma cells. Nature $1978 ; 275: 656$ $-8$.

16. Sloane AJ, Raso V, Dimitrov DS, et al. Marked structural and functional heterogeneity in CXCR4: separation of HIV-1 and SDF-1alpha responses. Immunol Cell Biol $2005 ; 83$ : 129 43.

17. Talbott RL, Sparger EE, Lovelace KM, et al. Nucleotide sequence and genomic organization of feline immunodeficiency virus. Proc Natl Acad Sci USA $1989 ; 86: 5743$ - 7.

18. Hohdatsu T, Hirabayashi H, Motokawa K, Koyama H. Comparative study of the cell tropism of feline immunodeficiency virus isolates of subtypes A,B and D classified on the basis of the env gene V3-V5 sequence. J Gen Virol $1996 ; 77: 93$ - 100.

19. Hohdatsu T, Motokawa K, Usami M, Amioka M, Okada S, Koyama H. Genetic subtyping and epidemiological study of feline immunodeficiency virus by nested polymerase 
chain reaction-restriction fragment length polymorphism analysis of the gag gene. $J$ Virol Methods $1998 ; 70: 107-11$.

20. Kusuhara H, Hohdatsu T, Okumura M, et al. Dual-subtype vaccine (Fel-O-Vax FIV) protects cats against contact challenge with heterologous subtype B FIV infected cats. Vet Microbiol $2005 ; 108: 155-65$.

21. Besmer P, Smotkin, D, Haseltine W, et al. Cold Spring Harbor Symp Quant Biol 1975 ; 39 : $1103-7$.

22. Brunner D, Pedersen NC. Infection of peritoneal macrophages in vitro and in vivo with feline immunodeficiency virus. J Virol $1989 ; 63: 5483-8$.

23. Ichiyama K, Yokoyama-Kumakura S, Tanaka Y, et al. A duodenally absorbable CXC chemokine receptor 4 antagonist, $\mathrm{KRH}-1636$, exhibits a potent and selective anti-HIV-1 activity. Proc Natl Acad Sci USA $2003 ; 100: 4185$ - 90.

24. Willett BJ, Picard L, Hosie MJ, Turner JD, Adema K, Clapham PR. Shared usage of the chemokine receptor CXCR4 by the feline and human immunodeficiency viruses. J Virol 1997 ; $6407-15$. 
25. Endres MJ, Clapham PR, Marsh M, et al. CD4-independent infection by HIV-2 is mediated by fusin. Cell $1996 ; 87: 745-56$.

26. Murphy PM. The molecular biology of leukocyte chemoattractant receptors. Annu Rev Immunol $1994 ; 12: 593-633$.

27. Huang Y, Paxton WA, Wolinsky SM, et al. The role of a mutant CCR5 allele in HIV-1 transmission and disease progression. Nature Med $1996 ; 2: 1240$ - 3.

28. Bieniasz PD. Restriction factors : a defense against retroviral infection. Trends Microbiol $2003 ; 11: 286-91$.

29. Saenz DT, Teo W, Olsen JC, Poeschla EM. Restriction of feline immunodeficiency virus by Ref1, Lv1, and primate TRIM5a proteins. J Virol 2005; 79 : 15175 - 88. 


\section{Figure Legends}

Figure 1 Agarose gel showing the results of PCR amplification of DNA for the FIV gag-, and env- gene regions obtained from the indicated cells. A nested PCR was used to amplify the FIV gag or env gene sequence as described in Materials and Methods. The positions of bands of $329 \mathrm{bp}$ and $873 \mathrm{bp}$ corresponding to gag and env, respectively, are shown. Lanes: M, DNA size marker (100-bp ladder); 1 and 2 (duplicate), mock-infected 3201 cells; 3 to 6 (quadruplicate), 3201-S cells; 7 and 8 (duplicate), 3201/FIV cells.

Figure 2 Flow cytometric analysis of CXCR4 expression on 3201, 3201-S, and 3201/FIV cells. Cells were stained with anti-CXCR4 44717 MAb, followed by FITC-conjugated anti-lgG (bold line). For all panels, data are shown as relative cell number ( $y$-axis) plotted against relative fluorescence intensity ( $x$-axis). The background staining is the signal derived from incubation of the cells with the FITC-conjugated secondary antibody only (dashed line). Mean fluorescence intensity (MFI) is indicated in parentheses.

Figure 3 Comparative CXCR4 expression on 3201, 3201-S, and 3201/FIV cells assessed by flow cytometry using a panel of MAbs. Cells were incubated with anti-CXCR4 MAb clones 44708,44716 or 44717 , followed by staining with FITC secondary antibody. Designations are the same as in the legend to Fig. 2.

Figure 4 Effect of FIV infection or reinfection on the expression of CXCR4 on 
3201 cells and 3201-S cells. Samples of mock-infected 3201, and FIV-infected 3201 or

FIV-reinfected 3201-S cells were collected at the indicated time points, and processed for analysis by flow cytometry. Cells were incubated with anti-CXCR $444717 \mathrm{MAb}$, followed by staining with FITC secondary antibody. Designations are the same as in the legend to Fig. 2 . Cells were processed in parallel for analysis by the PCR (Table 1).

Figure 5 Comparison of SDF-1a responsiveness in 3201 and 3201-S cells. Cells were loaded with Indo-1 AM $(1 \mu \mathrm{M})$ and incubated in RPMI 1640 medium for 30 min at $37^{\circ} \mathrm{C}$ in $5 \% \mathrm{CO}_{2}$, followed by stimulation at the indicated time point (arrow) with $1 \mu \mathrm{g} / \mathrm{ml} \mathrm{SDF}-1 \alpha$. The intracellular $\mathrm{Ca}^{2+}$ concentrations were calculated as described in Materials and methods. 

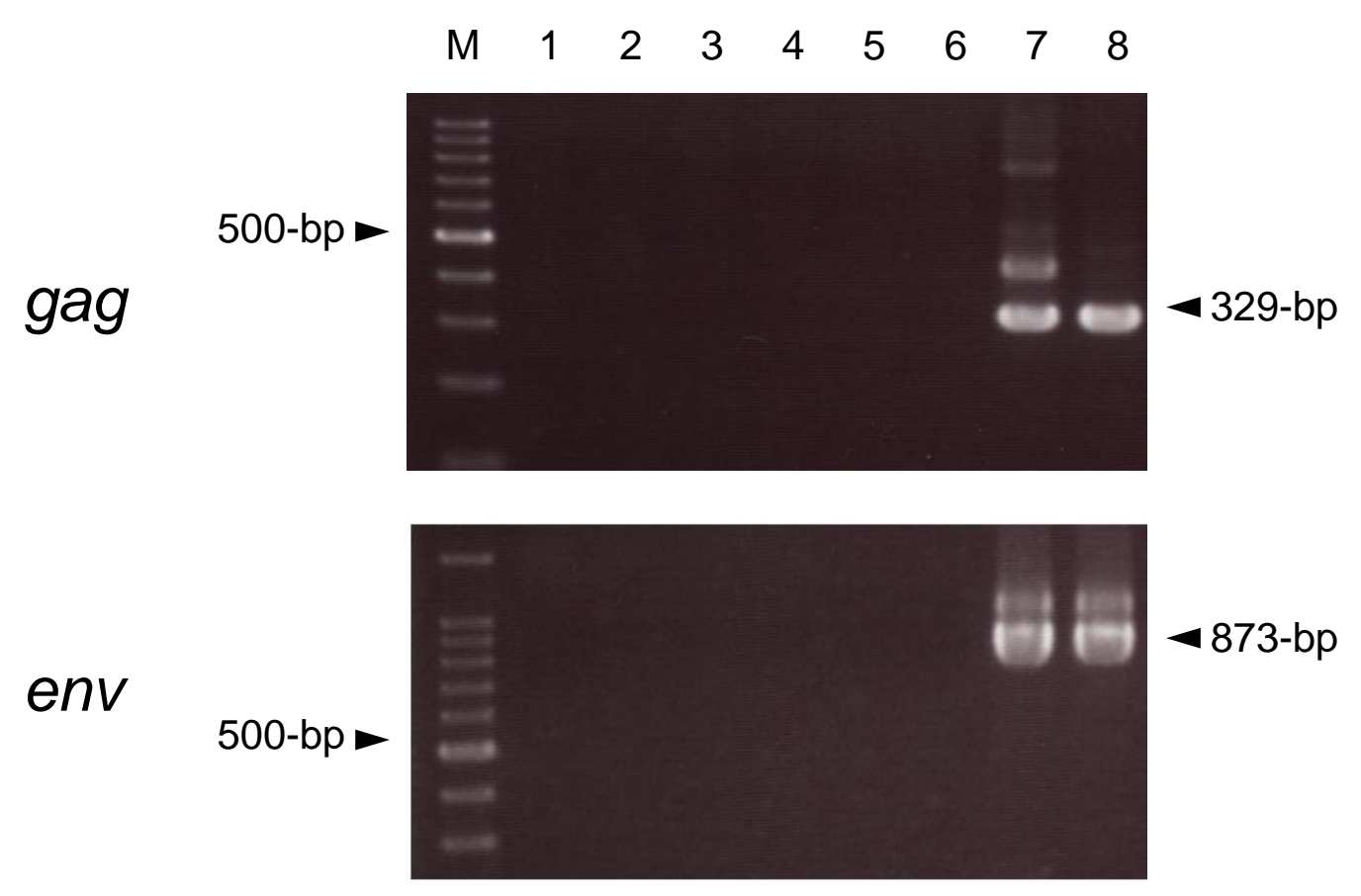


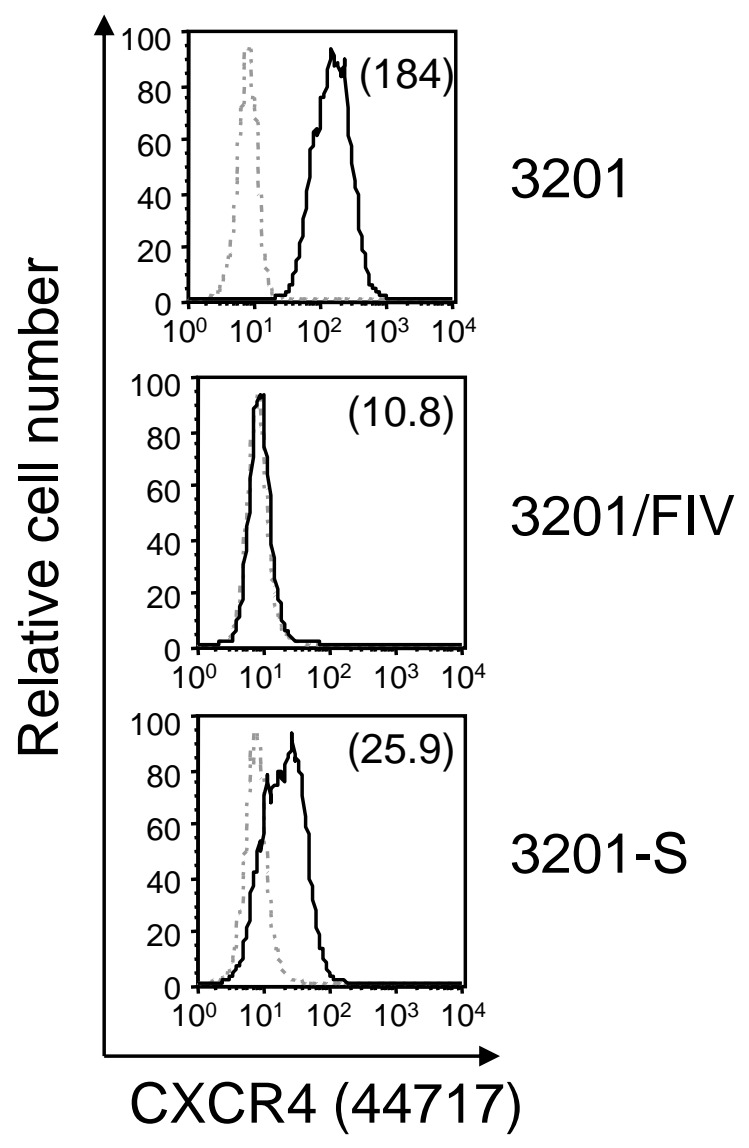

Control (2ndary antibody alone) CXCR4 


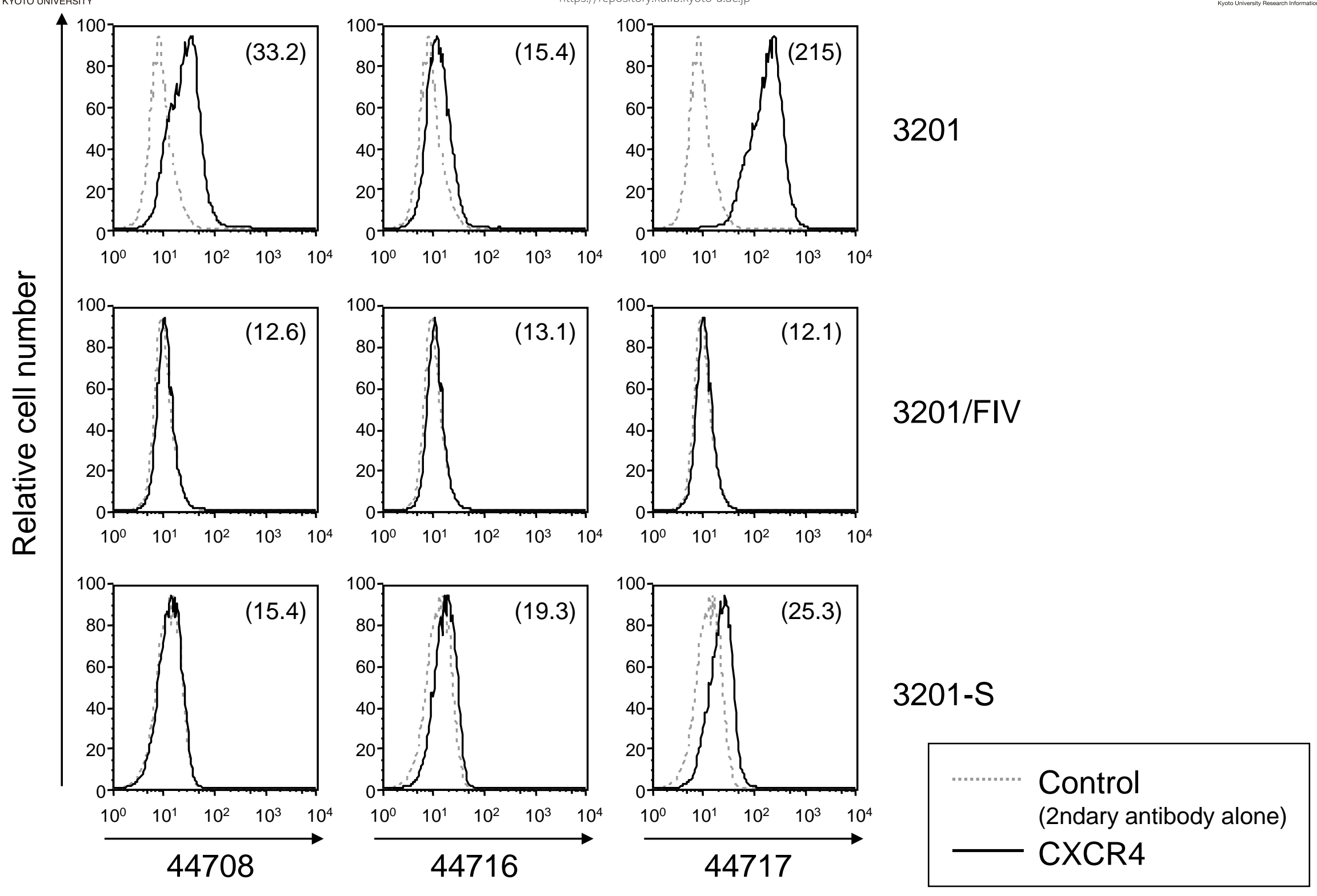




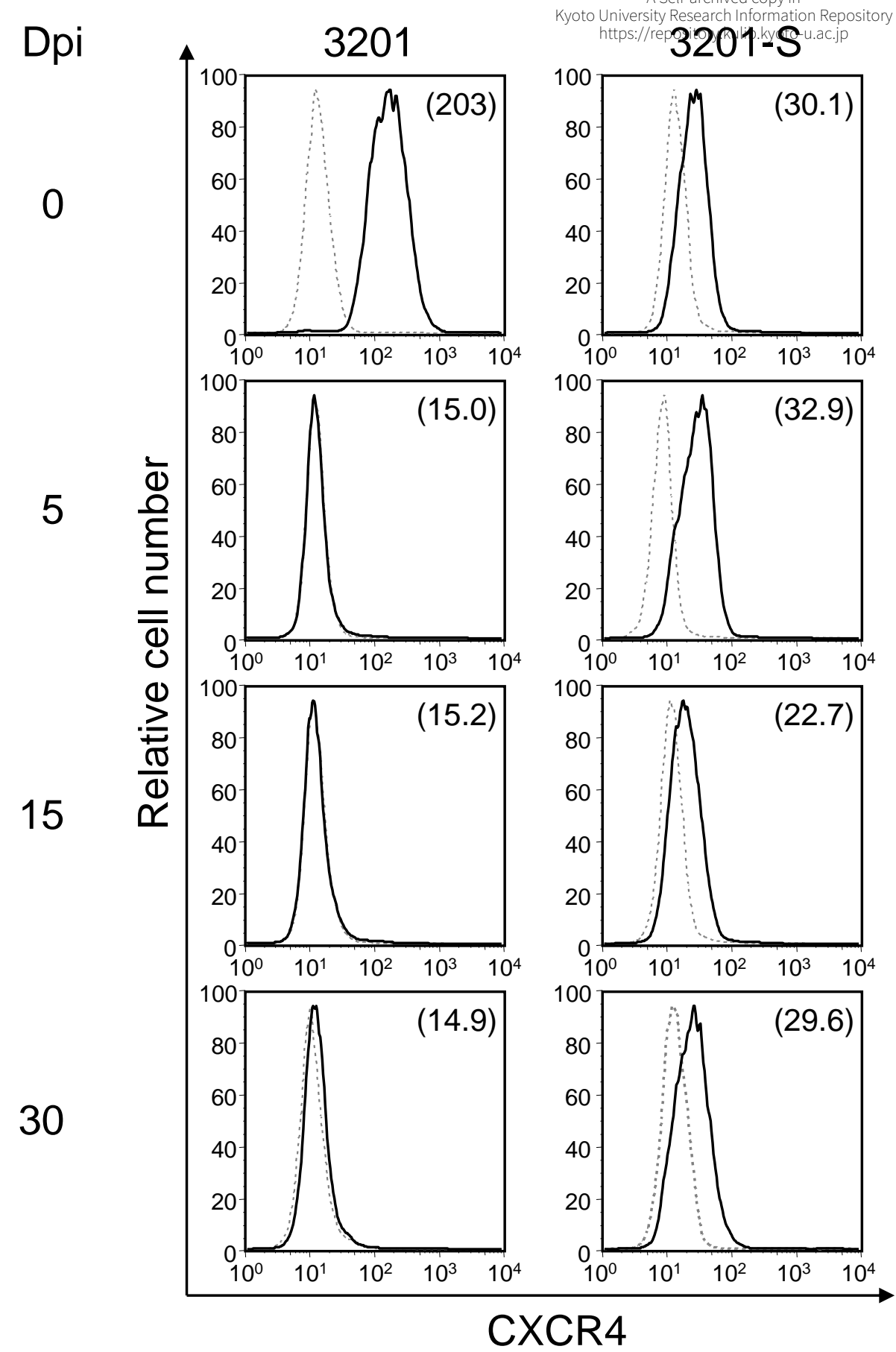

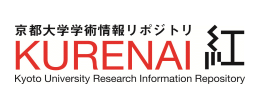




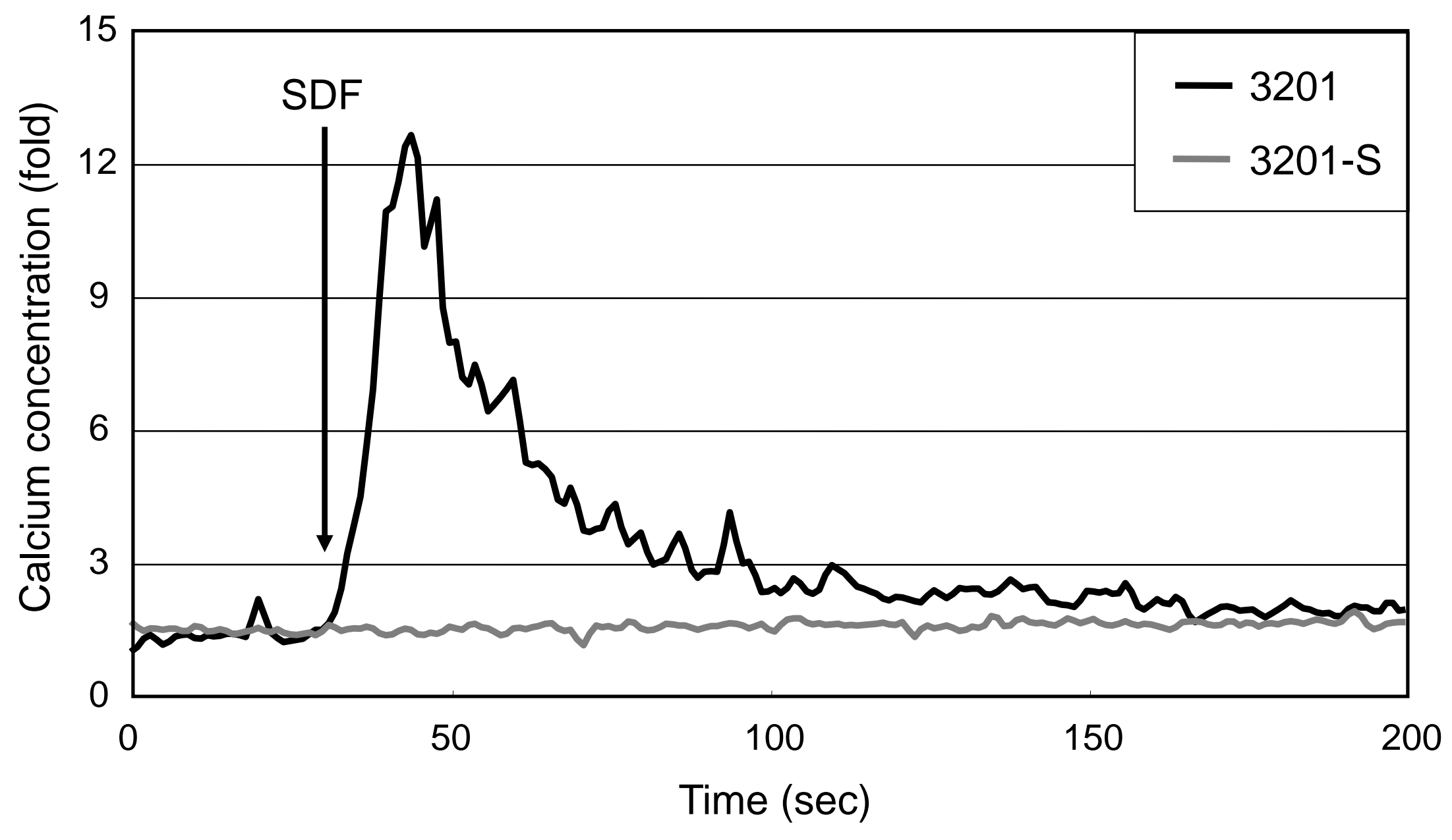


Table 1 Detection of FIV DNA in the indicated cells after infection or reinfection with FIV

\begin{tabular}{|c|c|c|c|c|c|}
\hline \multirow{2}{*}{ Cell } & \multirow{2}{*}{ Assay type } & \multicolumn{4}{|c|}{ Days after infection (3201) or reinfection (3201-S) } \\
\hline & & 0 & 5 & 15 & 30 \\
\hline \multirow{3}{*}{3201} & Nested PCR ${ }^{a}$ & - & + & + & + \\
\hline & Real - time PCR ${ }^{b}$ & 0 & 6,210 & 47,043 & 18,274 \\
\hline & & 0 & 5,905 & 45,772 & 22,559 \\
\hline \multirow{3}{*}{$3201-S$} & Nested PCR & - & + & - & - \\
\hline & Real - time PCR & $\mathrm{ND}$ & 7 & ND & ND \\
\hline & & ND & 4 & ND & ND \\
\hline
\end{tabular}

${ }^{a}+$, positive result : -, neaative result in nested PCR assav.

${ }^{\mathrm{b}}$ Result of real-time PCR assay is expressed as copy number per $10^{6}$ cells.

Experiments were carried out in duplicate.

ND, not done. 